\title{
Investigation of the Relationship between Care Giving Burden and Quality of Life of Caregivers of Cancer Patients
}

\author{
Serap Gokce Eskin ${ }^{1}$, Ruveyda Yuksel², Hulya Bulut ${ }^{3}$ \\ ${ }^{1}$ Department of Health Science, Adnan Menderes University, Aydin, Turkey. ${ }^{2}$ Department of Nursing, Adnan \\ Menderes University, Aydin, Turkey. ${ }^{3}$ Department of Chest Diseases, SBU, Izmir Suat Seren Chest Diseases \\ and Surgery Training and Research Hospital, Research and Development Unit, Izmir, Turkey.
}

\section{ABSTRACT}

\section{BACKGROUND}

We wanted to evaluate the effect of caregiver burden on quality of life of the cancer patient caregivers.

\section{METHODS}

This research was conducted as an analytical cross-sectional study. The study population comprised of caregivers of patients, who were receiving treatment in the chemotherapy unit of a branch hospital. 466 caregivers who participated in the study comprised the sample of the research. The research data was collected using "Demographic Data Form", "Zarit Burden Interview", and "Caregiver Quality of Life Scale-Cancer".

\section{RESULTS}

Among the participants, $71.2 \%$ were females and average age was $44.80 \pm 13.76$. It was concluded that certain qualifications of the caregivers such as educational status, income levels, another family member with cancer diagnosis, and having support in caregiving process affected the quality of life of the caregivers. Burden scale score was 32.41 , and quality of life scale score was 89.83 . It was determined that there was a negative and strong relationship between the burden scale and quality of life scale. Presence of another individual with cancer in the family, receiving support, conditions arising from the caregiving process, such as affected health, having marital difficulties were found to affect the burden of caregiving.

\section{CONCLUSIONS}

It was determined that there was a negative, strong relationship between the caregiver burden and quality of life. In line with these results, it is suggested that interventional and qualitative studies should be conducted on the caregivers in order to define their caregiver burden and evaluate their lifestyles.
Corresponding Author: Dr. Serap Gokce Eskin, PhD, Assistant Professor, Adnan Menderes University, Faculty of Health Science, Efeler / Aydin- Turkey. E-mail: serap.gokce@adu.edu.tr

DOI: $10.14260 /$ jemds/2021/123

How to Cite This Article: Gokce Eskin S, Yuksel R, Bulut $H$. Investigation of the relationship between care giving burden and quality of life of caregivers of cancer patients. J Evolution Med Dent Sci 2021; 10(09):567-572, DOI: $10.14260 /$ jemds/2021/123

Submission 21-10-2020,

Peer Review 06-01-2021, Acceptance 12-01-2021, Published 01-03-2021.

Copyright (c) 2021 Serap Gokce Eskin et al. This is an open access article distributed under Creative Commons Attribution License [Attribution 4.0 International (CC BY 4.0)]

\section{KEY WORDS}

Cancer, Care Giver, Burden, Quality of Life 


\section{BACKGROUND}

Cancer can affect anyone and it represents a tremendous burden on patients, families, and societies. Cancer is the second leading cause of death globally and was estimated to account for 9.6 million deaths in $2018 .{ }^{1}$

Cancer is a disease not only of a patient but also of their family. Patients and their caregivers are directly affected by cancer-related difficulties and the chief problem that caregivers experience is the burden of care..$^{2-4}$ In the literature, the burden of care, which arises as a result of providing care and which is defined as a subjective experience that is perceived as highly stressful by a caregiver, emerges as an important problem. ${ }^{5}$ Family members support their patient financially and socially and also take on the responsibility of meeting their patient's need for individual care. Considering these responsibilities and burdens, a caregiver usually focuses on meeting their patient's needs and sets aside their own physical, spiritual and emotional needs. ${ }^{6}$ According to a study conducted in Turkey, the quality of life of those who are responsible for the care of cancer patients is influenced by biological, psychological, socio-cultural, environmental and politico-economic factors; and their quality of life decreases in the process. ${ }^{7}$ Some studies reported that caregivers are affected by cancer at least as much as patients, experience high burden of care, perceive high levels of stress, and live a life that is negatively affected as they provide patient care. . $^{8}$

In providing quality care to cancer patients, evaluating the physical, social, psychological, and economic needs of caregivers had been important.4, 0 n the basis of the evaluations conducted, it is recommended that the needs of caregivers be met and that the family be placed at the center of care. ${ }^{10}$ Moreover, studies suggested that healthcare professionals should periodically diagnose and assess care burden to reduce the burden experienced by the relatives of cancer patients. ${ }^{7,9,11}$ In this light, a nurse, who plays an important role in a team that provides care to cancer patients, must conduct a holistic assessment of cancer patients and their relatives and then create a care plan. Determining the effect of caregiving burden on the quality of life of cancer patients' caregivers is thus extremely important. This research, which aimed to evaluate the care burden and the quality of life of family members who provide care for their cancer patients, is expected to serve as a guide in the planning of nursing care.

\section{METHODS}

This research is an analytical cross-sectional study that was conducted in a chemotherapy unit of a branch hospital in one of the Western provinces. The study population consisted of the caregivers of patients being treated in the chemotherapy unit of the said hospital between February 2017 and July 2018. The sample size was calculated using the G-Power program, and its effect size and alpha error were calculated to be 0.25 and 0.05 , respectively; the sample size was calculated to be 269 with $80 \%$ power. Given the subject loss in the sample, 20 $\%$ was allocated as substitute; therefore, the number of the sample was adjusted to 323 , we conducted a G-power analysis to determine the minimum number of sample size of study. We aimed not to go below this number. 466 participating caregivers were ultimately included in the study population.

\section{Data Collection Tool}

Data was collected by using a survey form. The survey form consisted of three parts, Demographic Data Form, Zarit Burden Interview (ZBI), and Caregiver Quality of Life Scale-Cancer (CQOLC) (İnci \& Erdem 2008, Yakar \& Pınar 2013.)

\section{Demographic Data Form}

This form was prepared by the researchers in line with the relevant literature; this form includes questions that determine the socio-demographic characteristics of the caregivers and their conditions concerning the caregiving practice.

\section{$Z B I$}

The ZBI was developed by Zarit et al. in $1980 .{ }^{12}$ This scale is used to rate the difficulty experienced by individuals who provide care to those who are in need of care. This 22-item scale can be filled out either by the responder or by the investigator, and it measures the impact of caregiving on a caregiver's life. Each item in this Likert-type scale includes five choices. The total score would range from 0 to 88; the higher the score, the heavier the burden. The internal consistency of this scale was calculated to be 0.91 . The Turkish version of this scale was developed by İnci and Erdem (2008), who calculated the internal consistency of this scale to be $0.95 .{ }^{13}$ In our study, the internal consistency of this scale is 0.91 .

\section{CQOLC}

Weitzner's CQOLC is a self-administered rating scale designed to assess the quality-of-life issues experienced by the family caregivers of cancer patients. A questionnaire based on the above CQOLC scale was developed by Weitzner et al., 1999.14 It measures important aspects of quality of life: physical functioning, emotional functioning, family functioning, and social functioning. Out of the 35 items in the questionnaire, 10 are about burden, 7 are about disruptiveness, 7 are about positive adaptation, 3 are about financial concerns, and 8 are about additional factors. The maximum score for this instrument is 140, and higher scores reflects better QOL. When used in family caregiver of patients with cancers, this scale demonstrated validity correlation coefficient of 0.95 , and Cronbach's $\alpha$ of 0.91 .14 The Turkish version of this scale was developed by Karabuga Yakar and Pinar. ${ }^{15}$ The Cronbach's $\alpha$ of this scale was calculated to be 0.87 .

With the use of a survey form, data was collected from the caregivers of the patients. An informed consent form was filled out and signed by the patients' relatives who volunteered to participate in this study. The survey forms could be accomplished within 20 minutes in average.

\section{Statistical Analysis}

The SPSS 22.0 software package was used to encode and analyse the data. Normal distribution analyses were initially conducted. In this context, the Gaussian curve was evaluated, and the mean score, the minimum and maximum score range, and the significance level of the Kolmogorov-Smirnov test was calculated. Based on the socio-demographic characteristics of 
the caregivers, $\mathrm{t}$-test and Pearson correlation analysis were employed to compare the average scores for the ZBI and the CQOLC; a type 1 error level (significance level) was set at $\mathrm{p}<$ 0.05 .

\section{Ethical Aspect of the Research}

This study was carried out in accordance with the principles of the Helsinki Declaration. The research activities reported in this manuscript were conducted in accordance with a protocol approved by ethics committee for Non-Invasive Clinical Research of the Faculty of Health Sciences at Aydın Adnan Menderes University on February 28, 2018 (92340882050.04.04). A written permission was also sought from the institution where this study was carried out.

\begin{tabular}{|c|c|c|c|}
\hline \multicolumn{4}{|c|}{ RESULTS } \\
\hline \multicolumn{2}{|c|}{ Characteristics of Caregivers } & $\mathbf{n}$ & $\%$ \\
\hline \multirow{2}{*}{ Gender } & Woman & 332 & 71,2 \\
\hline & Man & 134 & 28,8 \\
\hline \multirow{3}{*}{ Education } & Primary school & 190 & 40.7 \\
\hline & High school & 169 & 36,3 \\
\hline & University & 107 & 23,0 \\
\hline \multirow{2}{*}{ Marital Status } & Married & 94 & 20,2 \\
\hline & Single & 372 & 79,8 \\
\hline \multirow{3}{*}{ Living Place } & Village / Township & 382 & 82,0 \\
\hline & County center & 64 & 13,7 \\
\hline & City center & 20 & 4,3 \\
\hline \multirow{2}{*}{ Social Security } & No & 413 & 88,6 \\
\hline & Yes & 53 & 11,4 \\
\hline \multirow{2}{*}{ Employment } & Yes & 220 & 44,2 \\
\hline & No & 246 & 55,8 \\
\hline \multirow{3}{*}{ Monthly Family Income } & Income less than expense & 145 & 31,1 \\
\hline & Income equivalent to the expense & 259 & 55,6 \\
\hline & Income more than expenses & 62 & 13,3 \\
\hline \multirow{2}{*}{ Living with Patient } & Yes & 313 & 67,2 \\
\hline & No & 153 & 32,8 \\
\hline \multirow{2}{*}{ Chronic Illness } & No & 314 & 67,4 \\
\hline & Yes & 152 & 32,6 \\
\hline \multirow{2}{*}{ Another Cancer Patient in Family } & No & 288 & 61,8 \\
\hline & Yes & 178 & 38,2 \\
\hline \multirow{2}{*}{ Social Support of the Caregivers } & No & 327 & 70,2 \\
\hline & Yes & 139 & 29,8 \\
\hline Duration of Caregiving (months) & $0-6$ & 148 & 31,75 \\
\hline \multirow{2}{*}{$\begin{array}{c}\text { Has your Health been Affected while } \\
\text { Giving Care? }\end{array}$} & No & 266 & 57,1 \\
\hline & Yes & 200 & 42,9 \\
\hline \multirow{2}{*}{$\begin{array}{c}\text { Did you have any Difficulties in Your } \\
\text { Marriage while Giving Care? }\end{array}$} & Yes & 348 & 74,7 \\
\hline & No & 118 & 25,3 \\
\hline \multirow{2}{*}{$\begin{array}{l}\text { Did you have Difficulty in the Family } \\
\text { While Caring? }\end{array}$} & No & 312 & 67,0 \\
\hline & Yes & 154 & 33,0 \\
\hline \multicolumn{2}{|c|}{ Characteristics of Patients } & n & $\%$ \\
\hline \multirow{4}{*}{ Age } & $15-29$ & 24 & 5,2 \\
\hline & $30-44$ & 50 & 10,7 \\
\hline & $45-59$ & 136 & 29,2 \\
\hline & $>60$ & 256 & 54,9 \\
\hline \multirow{2}{*}{ Gender } & Woman & 184 & 39,5 \\
\hline & Man & 282 & 60,5 \\
\hline \multirow{3}{*}{ Education } & Primary school & 301 & 64,59 \\
\hline & High school & 117 & 25,10 \\
\hline & University & 48 & 10,30 \\
\hline \multirow{2}{*}{ Marital Status } & Married & 327 & 69,77 \\
\hline & Single & 139 & 30,23 \\
\hline \multirow{5}{*}{ Cancer Type } & Lung Ca & 276 & 59,2 \\
\hline & Breast CA & 118 & 25,3 \\
\hline & Prostate Ca & 33 & 7,1 \\
\hline & Column Ca & 22 & 4,7 \\
\hline & Other & 17 & 3,7 \\
\hline
\end{tabular}

Among the participants, $71.2 \%$ were females and $28.8 \%$ were males; the average age of the participants was $44.80 \pm$ 13.76 years. Moreover, $55.8 \%$ were unemployed, $36.3 \%$ were high school graduates, $88.6 \%$ had a social security, $55.6 \%$ had incomes that were equal to their expenses, and $82 \%$ were living in city centers. In terms of caregiving, $67.2 \%$ were living at the same house with the patient; $31.8 \%$ had been providing caregiving service for $0-3$ months, whereas $22.1 \%$ had been caregiving for more than a year. Furthermore, $61.8 \%$ had another family member with a cancer diagnosis, $67.4 \%$ had a chronic illness, and $70.2 \%$ received professional support for their caregiving practice. It was found that the health status of $42.9 \%$ of the participants was influenced by the illness and the treatment of their patient; $33 \%$ had difficulties in family relationships and $25.3 \%$ had marital problems (Table 1).

As regards the patients being taken care of, $39.5 \%$ were females, $60.5 \%$ were males, $85.4 \%$ were married, $64.59 \%$ were primary school graduates, $78.3 \%$ were living in the city centers, $89.5 \%$ had a social security, $59.2 \%$ were receiving treatment for cancer, and $25.3 \%$ had breast cancer diagnosis (Table 1).

\begin{tabular}{|c|c|c|c|}
\hline & $\begin{array}{c}\text { Caregivers } \\
\text { Characteristics and } \\
\text { Caregiving Related } \\
\text { Variables }\end{array}$ & Mean \pm SD & P Test \\
\hline Age & & $44.80 \pm 13.76$ & $\begin{array}{l}R=-0.064 \\
P=0.170\end{array}$ \\
\hline Gender & $\begin{array}{l}\text { Female } \\
\text { Male }\end{array}$ & $\begin{array}{l}89.55 \pm 10.73 \\
90.50 \pm 12.95\end{array}$ & $\begin{array}{c}\mathrm{Z}=220.54 .500 \\
\mathrm{P}=0.885\end{array}$ \\
\hline Educational Level & $\begin{array}{l}\text { Primary School } \\
\text { Secondary School } \\
\text { High School } \\
\text { College }\end{array}$ & $\begin{array}{l}85.83 \pm 12.77 \\
89.94 \pm 10.45 \\
88.63 \pm 11.02 \\
92.90 \pm 12.22\end{array}$ & $\begin{array}{l}F=1.028 \\
P=0.421\end{array}$ \\
\hline Employment & $\begin{array}{l}\text { Yes } \\
\text { No }\end{array}$ & $\begin{array}{l}90.04 \pm 11.36 \\
89.58 \pm 11.47\end{array}$ & $\begin{array}{c}Z=26062.000 \\
P=0.491\end{array}$ \\
\hline Social Security & $\begin{array}{l}\text { No } \\
\text { Yes }\end{array}$ & $\begin{array}{l}86.75 \pm 10.20 \\
90.22 \pm 11.50\end{array}$ & $\begin{array}{c}Z=9201.000 \\
P=0.059\end{array}$ \\
\hline $\begin{array}{l}\text { Monthly family } \\
\text { income }\end{array}$ & $\begin{array}{l}\text { Income less than expense } \\
\text { Income equivalent to the } \\
\text { expense } \\
\text { Income more than } \\
\text { expenses }\end{array}$ & $\begin{array}{l}88.37 \pm 11.67 \\
89.69 \pm 11.17 \\
93.79 \pm 11.02\end{array}$ & $\begin{array}{l}F=0.812 \\
P=0.885\end{array}$ \\
\hline living place & $\begin{array}{l}\text { Village / Township } \\
\text { County center } \\
\text { City center }\end{array}$ & $\begin{array}{l}90.40 \pm 12.72 \\
86.14 \pm 10.40 \\
90.41 \pm 11.41\end{array}$ & $\begin{array}{l}F=0.991 \\
P=0.508\end{array}$ \\
\hline Living with patient & $\begin{array}{l}\text { Yes } \\
\text { No }\end{array}$ & $\begin{array}{l}90.24 \pm 11.67 \\
88.97 \pm 10.83\end{array}$ & $\begin{array}{l}\mathrm{T}=1.133 \\
\mathrm{P}=0.258\end{array}$ \\
\hline $\begin{array}{c}\text { Duration of caregiving } \\
\text { (months) }\end{array}$ & $\begin{array}{l}0-6 \\
\quad 7-12 \\
>12\end{array}$ & $\begin{array}{l}91.94 \pm 11.39 \\
87.85 \pm 11.20 \\
87.72 \pm 10.96\end{array}$ & $\begin{array}{l}\mathrm{F}=1.503 \\
\mathrm{P}=0.005^{*}\end{array}$ \\
\hline $\begin{array}{l}\text { Another cancer } \\
\text { patient in family }\end{array}$ & $\begin{array}{l}\text { No } \\
\text { Yes }\end{array}$ & $\begin{array}{l}87.37 \pm 10.61 \\
91.34 \pm 11.63\end{array}$ & $\begin{array}{c}Z=19965.000 \\
P=0.000^{*}\end{array}$ \\
\hline Chronic Illness & $\begin{array}{l}\text { No } \\
\text { Yes }\end{array}$ & $\begin{array}{l}90.89 \pm 11.58 \\
89.27 \pm 11.29\end{array}$ & $\begin{array}{l}T=-1.516 \\
P=0.130\end{array}$ \\
\hline $\begin{array}{l}\text { Social support of the } \\
\text { caregivers }\end{array}$ & $\begin{array}{l}\text { No } \\
\text { Yes }\end{array}$ & $\begin{array}{l}90.88 \pm 11.56 \\
87.35 \pm 10.67\end{array}$ & $\begin{array}{l}\mathrm{T}=3.084 \\
\mathrm{P}=0.002^{*}\end{array}$ \\
\hline $\begin{array}{l}\text { Has your health been } \\
\text { affected while giving } \\
\text { care? }\end{array}$ & $\begin{array}{l}\text { No } \\
\text { Yes }\end{array}$ & $\begin{array}{l}92.64 \pm 10.93 \\
86.08 \pm 10.96\end{array}$ & $\begin{array}{c}Z=17753.500 \\
P=0.000^{*}\end{array}$ \\
\hline $\begin{array}{c}\text { Did You Have } \\
\text { Difficulty In The } \\
\text { Family While Caring? }\end{array}$ & $\begin{array}{l}\text { No } \\
\text { Yes }\end{array}$ & $\begin{array}{c}93.62 \pm 10.37 \\
82.13 \pm 9.37\end{array}$ & $\begin{array}{c}Z=9816.500 \\
P=0.000^{*}\end{array}$ \\
\hline $\begin{array}{l}\text { Did you have any } \\
\text { difficulties in your } \\
\text { marriage while giving } \\
\text { care? }\end{array}$ & $\begin{array}{c}\text { No } \\
\text { Yes } \\
\mathrm{P}<0.05\end{array}$ & $\begin{array}{c}92.54 \pm 10.67 \\
81.82 \pm 9.63\end{array}$ & $\begin{array}{c}\mathrm{Z}=9211.500 \\
\mathrm{P}=0.000^{*}\end{array}$ \\
\hline
\end{tabular}

Our results demonstrated that certain qualifications, such as duration of caregiving practice $(p=0.000)$, having another family member with a cancer diagnosis $(p=0.000)$, and receipt of support in caregiving process $(p=0.002)$, affected the quality of life of the caregivers. It was also determined that 
gender, working status, social security, income levels, education, living place, living and health status did not influence the caregivers' quality of life (Table 2).

Our results further showed that duration of care $(\mathrm{p}=$ 0.000 ), the presence of another cancer patient in the family ( $p$ $=0.000$ ), and the receipt of support during the caregiving process $(p=0.044)$ affected the burden of care. Conditions arising from the caregiving process, such as affected health ( $\mathrm{p}$ $=0.000$ ), having domestic difficulties $p=0.00$ ), and having marital difficulties $(p=0.000)$, were also found to affect the burden of care. By contrast, the caregivers' sex, education, employment status, social security, income level, living place, living arrangement, and health status did not affect the quality of their caregiving activity. No significant correlation was found between age and the mean Zarit Burden Interview scores (Table 3).

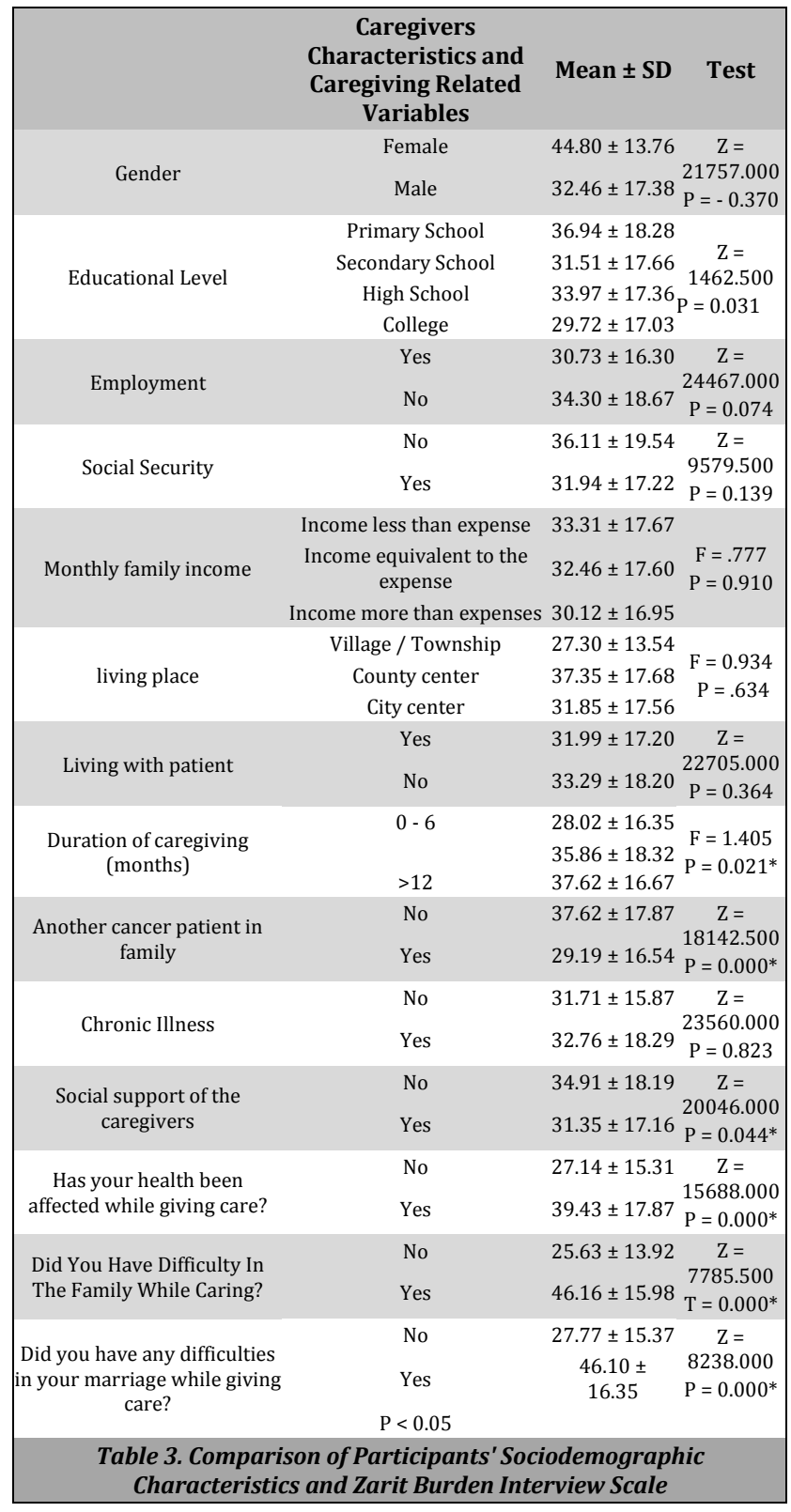

The average Zarit Burden Interview scores of the participants was $32.41 \pm 17.53$, and their average CQOLC scores was $89.83 \pm 11.41$. A negative strong relationship was observed between the Caregiver Burden Scale and the CQOLC $(\mathrm{r}=-0.676 ; \mathrm{p}=0.000)$ (Table 4).

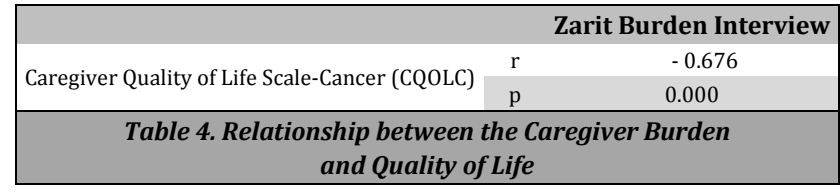

\section{DISCUSSION}

This study was conducted to determine the effect of caregiver burden on the quality of life of the caregivers of cancer patients

Caregiver burden is defined as the set of problems that individuals suffer from due to their caregiving activity. Our results showed that the caregiver burden of the participants was at a medium level. Similarly, Orak and Sezgin found that the cancer patients' caregivers they investigated experienced moderate burden. ${ }^{16}$ By contrast, Rha et al. (2015) reported a low level of caregiver burden among cancer patients' caregivers. ${ }^{8} \mathrm{~A}$ similar result was obtained by Yıldız and Ekinci who investigated the caregivers of child cancer patients. ${ }^{17}$

Our results showed that the factors that affect the caregiver burden include caregiving period, and having a cancer patient in the family to support while giving care to another patient.

Our results showed that the prolonged maintenance period increases the burden experienced by the caregivers. Individuals who provide care to patients with chronic illnesses may need to handle complex tasks, such as administering their patients' treatment, providing their care, ensuring their safety and giving them physical and emotional support. Prolonged provision of care has a negative impact on caregivers, both mentally and physically. ${ }^{18}$ as the duration of caregiving extends, the caregiver needs to take on their tasks for a longer period. However, the burden experienced by a caregiver when providing care is reduced when they receive support. In our study, the perceived caregiver burden was lower in individuals who received support during the caregiving process than in their counterpart. As reported in the literature, the presence of professional support groups or the receipt of social support exerts positive effect on the burden of care. Belgacem et al. showed that the training support program for individuals who provide care to cancer patients reduced the caregivers' burden of care ${ }^{19} \mathrm{Hu}$ et al. reported that caregivers who received more social support had a lower caregiver burden. ${ }^{20}$ Social support is presumed to provide caregivers with physical, social, and psychological convenience; also, it reduces stress and provides more energy and time for caregiving by saving time. Caregivers with social support will spend less time on the patient and more time for themselves. Furthermore, our results showed that the care burden of individuals who had difficulties in family relationships and who had marital problems was higher. Caregivers often face functional, physical, social, psychological and spiritual burdens. ${ }^{21}$ The burden of a caregiver in turn can lead to the deterioration of social relationships, to the emergence of psychological problems, and to decrease in the quality of life. One of the most important factors reducing the caregiver burden experienced by an individual is the social support they receive from family and friends. ${ }^{8}, 20,22$ However, given that individuals who experienced family or marital problems cannot receive this kind of support, and an increase in caregiver burden may be observed. 
In this study, the burden of caregivers, whose health is negatively affected, is higher. The care of cancer patients is difficult and troublesome for caregivers. ${ }^{23}$ Caregivers assist patients with their daily life activities, diet preparation, personal care regimes, physical symptom management, treatment management, compliance with medication, financial management, and household tasks as well as provide them with emotional and psychological support. 24,25 In meeting the needs of patients, the health of a caregiver can be adversely affected. For instance, the prognosis of caregivers with health problems may deteriorate.

The perceived caregiver burden in this study was lower in caregivers who had a family member with cancer. The presence of a cancer patient in a family for the first time is a physically, socially, and mentally difficult situation for a patient and for their family. The patient and their family may experience difficulties in accepting, coping, and managing the experience. However, individuals and caregivers can accept another similar situation more easily. They can manage the situation more successfully with the coping techniques that they have established in their previous experience.

In this study, the life quality levels of the caregivers were determined to be at a medium level. There are biological, psychological, socio-cultural, environmental, and politicoeconomic factors that influence the levels of quality of life of the caregivers of cancer patients. ${ }^{7,26}$ One or several of these factors may cause a decrease in the quality of life of an individual. It was reported that having a social security and a certain economic level positively influence the anxiety level of caregivers. ${ }^{27,28}$. Okçin reported that the efforts related to the diagnosis and treatment of a cancer patient and the side effects and complications brought about by the disease caused heavy burden materially and economically both on the patient and on the caregiver. ${ }^{28}$ The same study reported that an economic situation adversely affected the caregivers of cancer patients. In our research, the majority of the participants had a social security, and they did not characterize their economic situation as poor; these characteristics are considered to have exerted a positive impact on their quality of life.

Furthermore, the quality of life of the caregivers decreases as the duration of the caregiving practice increases. Orak and Sezgin reported that caregivers use coping mechanisms during the first 6 - 12 months; beyond this period, their ability to cope with the demands of their caregiving practice decreases and thus they suffer from exhaustion along with a decreasing quality of life. ${ }^{16}$ Caregiving is a process that exerts numerous negative effects on an individual. As the caregiving period increases, the problems faced by the caregiver increase as well. With a decreasing quality of life, the lifestyle of the individual and the family, as well as their expectations will change accordingly. ${ }^{11,29}$

Our results demonstrated that having another family member with a cancer diagnosis affects the quality of life of the caregivers. Yıldız and Kabataş Ekinci reported similar results. Having other family members with cancer diagnosis can lead to economic, mental, and physical difficulties in individuals. ${ }^{17}$ This situation leads to a decrease in the quality of life of caregivers.

The quality of life of caregivers who receive social support was determined to be higher. Consistent with this finding, previous results demonstrated that receiving support during the care process affects the quality of life of the caregivers of cancer patients 11,20

As shown by our results, the quality of life decreased as the caregiver burden increased. Studies demonstrated that the caregiver burden and the quality of life of the caregivers of cancer patients are correlated. Okçin reported that the quality of life of family members was adversely affected as the caregiver burden increased and as their lives were adversely affected. ${ }^{28}$ Care, treatment, and monitoring of a cancer patient require the provision of support to a patient particularly in certain areas, such as in coping with the illness and with the treatment process, in emotional, physical, financial, and spiritual aspects, and in personal care. The caregiver who provides this support may not be able to meet their own physical, emotional and social needs. Such a situation can lead to a decrease in quality of life. ${ }^{11}$

\section{Limitations of the Research}

The major limitation of this study is the low number of participants. Thus, the results cannot be generalized to the general population. This study is a single-centre research and thus the current findings should be interpreted with caution.

\section{CONCLUSIONS}

In this research, the participants' quality of life was found to be affected by certain factors, such as work status, duration of the caregiving activity, having another family member with cancer diagnosis, receipt of support during caregiving process, being affected by the illness, the treatment process of a relative, having marital problems, and having problems in family relationships. On the basis of this finding, it is suggested that interventional and qualitative studies involving caregivers be conducted in order to intensively investigate the caregiver burden and their lifestyles.

Data sharing statement provided by the authors is available with the full text of this article at jemds.com.

Financial or other competing interests: None.

Disclosure forms provided by the authors are available with the full text of this article at jemds.com.

Serap Gokce Eskin - Conceptualization, Methodology, Software, Writing, Formal Analysis, Visualization; Ruveyda Yuksel - Data curation, Formal analysis, Writing - Original draft preparation; Hulya Bulut - Methodology, Visualization, Investigation. Resources, Supervision.

\section{REFERENCES}

[1] World Health Organization. Cancer Fact Sheet (2020, July 10) topics/cancer\#tab=tab_1 https://www.who.int/health-

[2] Kim Y, Carver C. Frequency and difficulty in caregiving among spouses of individuals with cancer: effects of adult attachment and gender. Psychooncology 2007; 16(8):714-23.

[3] Tekin Eraslan P, Şahin Cankurtaran E. The spouses and Intimate families of cancer patients. Turkiye Klinikleri J Psychiatry-Special Topics 2014; 7(4):50-8. 
[4] Toptaş Kılıc S, Oz F. Problems and quality of life of family members caring cancer patients and interventions. J Hacettepe University Faculty of Nursing 2019; 6(3):195203.

[5] Schebring M. Effect of caregiver perception of preparedness on burden in an oncology population. Oncol Nurs Forum 2002; 29(6):E70-6.

[6] Lapid MI, Atherton PJ, and Kung S, et al. Cancer caregiver quality of life: need for targeted intervention. Psychooncology 2016; 25(12):1400-7.

[7] Kaya N, Bolol N, Ülgen S, et al. Quality of life and influencing factors in caregivers of patients with cancer. Clin Exp Health Sci 2017; 8(1):25-36.

[8] Rha SY, Park Y, Song SK, et al. Caregiving burden and health-promoting behaviors among the family caregivers of cancer patients. Eur J Oncol Nurs 2015; 19(2):174-81.

[9] Yıldız E, Dedeli Ö, Pakyüz CS. Evaluation of care burden and quality of life among family caregivers of patıents with cancer. HEAD 2016; 13(3):216-25.

[10] Ferrell BR, Temel JS, Temin S, et al. Integration of palliative care into standard oncology care: American Society of Clinical Oncology Clinical Practice Guideline Update. J Clin Oncol 2017; 35(1):96-112.

[11] Given BA, Given CW, Sherwood P. The challenge of quality cancer care for family caregivers. Semin Oncol Nurs 2012; 28(4):205-12.

[12] Zarit SH, Reever KE, and Back-Peterson J. Relatives of the impaired elderly: correlates of feelings of burden. Gerontologist 1980; 20(6):649-55.

[13] Inci FH, Erdem M. Validity and reliability of the burden interview and its adaptation to Turkish. Journal of Atatürk University School of Nursing 2008; 11(4):85-95.

[14] Weitzner MA, Jacobsen PB, Wagner JR, et al. The caregiver quality of life index-cancer (CQOLC) scale: development and validation of an instrument to measure quality of life of the family caregiver of patients with cancer. Qual Life Res 1999; 8(1-2):55-63.

[15] Yakar HK, Pinar R. Reliability and validity of Turkish version of the caregiver quality of life index cancer scale. Asian Pac J Cancer Prev 2013; 14(7):4415-9.

[16] Orak OS, Sezgin S. The investigation of caregiver burden in family members of cancer patients. J Psy Nurs 2015; 6(1):33-9.
[17] Yıldız MK, Ekinci M. The relation between anger expression styles and caretaking burden of family members of cancer patients and affecting factors. HEAD 2017; 14(3):176-84.

[18] Lu L, Wang L, Yang X, et al. Zarit caregiver burden interview: development, reliability and validity of the chinese version. Psychıat Clın Neurosci 2009; 63(6):7304.

[19] Belgacem B, Auclair C, Fedor MC, et al. A caregiver educational program improves quality of life and burden for cancer patients and their caregivers: a randomised clinical trial. Eur J Oncol Nurs 2013; 17(6):870-6.

[20] Hu X, Peng X, Su Y, et al. Caregiver burden among Chinese family caregivers of patients with lung cancer: a crosssectional survey. Eur J Oncol Nurs 2018; 37:74-80.

[21] Grant M, Sun V, Fujinami R. Family caregiver burden, skills preparedness, and quality of life in non-small cell lung cancer. Oncol Nurs Forum 2013; 40(4):337-46.

[22] Northouse L, Williams AL, Given B, et al. Psychosocial care for family caregivers of patients with cancer. J Clın Oncol 2012; 30(11):1227-34.

[23] Romito F, Goldzweig G, Cormio C, et al. Informal caregiving for cancer patients. Cancer 2013; S11:2160-9.

[24] Girgis A, Lambert SD. Caregivers of cancer survivors: the state of the field. Cancer Forum 2009; 33(3):167-71.

[25] Girgis A, Lambert S, Johnson C, et al. Physical, psychosocial, relationship, and economic burden of caring for people with cancer: a review. J Oncol Pract 2013; 9(4):197-202.

[26] Yun HY, Rhee YS, Kang IO, et al. Economic burdens and quality of life of family caregivers of cancer patients. Oncology 2005;68(2-3):107-14.

[27] Sarıtaş SÇ, Büyükbayram Z. The anxiety level of chemotherapy receiving patients and their caregivers and affecting factors. TAF Preventive Medicine Bulletin 2016; 15(2):141-50.

[28] Okçin F. Validity and reliability study of the quality of life scale in a family setting that cares for cancer patients. Ege University Institute of Health Sciences. Izmir Ph.D. Thesis 2007.

[29] Oksuz E, Barıs N, Aslan F, et al. Psychiatric symptom levels and caregiver burden of caregivers on patients receiving chemotherapy. Anatol J Clin Investig 2013; 7(1):24-35. 